\title{
Educação e relações étnico-raciais: a Lei 10.639/03, a formação docente e o espaço escolar
}

\author{
Wilker Solidade Silva* \\ Eugênia Portela Siqueira Marques ${ }^{* *}$
}

\begin{abstract}
Resumo
Este trabalho discute os procedimentos metodológicos e os resultados de uma pesquisa acerca das Políticas Públicas para a Educação das relações étnico-raciais a partir das possibilidades abertas pela Lei 10.639/2003 que alterou a LDBEN (Lei 9.394/96) e tornou imperativo educativo a História da África e da Cultura afro-brasileira nos sistemas de ensino do Brasil. Tece considerações sobre a efetivação de práticas pedagógicas voltadas para o reconhecimento e o respeito à diversidade étnico-racial, à superação da discriminação racial e a afirmação da identidade da criança negra. Para tanto, apresentamos os desafios e limites da ação docente no processo de implementação dessa Lei. A pesquisa de cunho qualitativo utiliza procedimentos metodológicos de análise documental e aplicação de questionários. Os estudos de Gomes (2012), Kadlubitski e Junqueira (2010), Cavalleiro (2005), Gonçalves (2001), entre outros, referendaram a perspectiva teórica das análises. Os resultados indicam que passados dez anos de implantação da Lei 10.639/2003, o conhecimento do que ela preconiza é ainda razoavelmente incipiente. Os docentes colaboradores com a pesquisa identificam o objetivo da Lei, mas não reconhecem ou ignoram a presença do preconceito e da discriminação racial no espaço escolar. A pesquisa apontou para a necessidade de as redes de ensino desenvolver programas de formação continuada de professores na perspectiva da construção de uma educação pública de qualidade, democrática e antirracista.
\end{abstract}

Palavras-chave: Educação. Relações étnico-raciais; Formação docente.

\section{Education and ethnic-racial relations: the Law 10.639/03, teacher education and school space}

\begin{abstract}
The purpose of this essay is to analyze the methodological procedures and the results of a research on Public Policy for the Education of ethnic-racial and the possibilities opened by the Law 10.639/2003, which modifies the LDBEN (9.394/96) and made compulsory the education of History African culture and Afro-Brazilian education systems in Brazil. Reflect on the effectiveness of teaching practices aimed at the recognition and respect for ethnic and racial diversity, to overcome racial discrimination and affirmation of the black child's identity. Therefore, we present the challenges and limitations of the teaching in the process of implementing this law. The research uses qualitative methodological procedures for the analysis of documents and semi-structured interviews. The Gomes studies (2012), and Kadlubitski Junqueira (2010), Cavalleiro (2005), Goncalves (2001), among others, are references to theoretical analysis. The partial results Indicate that after ten years enforcement 10.639/2003 Law, the knowledge is still quite incipient. Teachers research collaborators could identify the purpose of the law, but not acknowledge or ignore the presence of racial prejudice and discrimination in school. The research pointed to the need for school systems to develop continuing education programs for teachers in the perspective of building a quality public education, democratic and anti-racist.
\end{abstract}

Keywords: Education; Ethnic-racial relations; Teacher training.

Há mais de uma década, as discussões em torno das questões étnico-raciais contribuíram para repensar sobre o papel da escola e a formação docente no sentido de garantir novos espaços pedagógicos que propiciem o reconhecimento e a valorização das múltiplas identidades que compõem a população brasileira. As pressões do Movimento Negro Brasileiro foram imprescindíveis nesse processo de luta pelos direitos da população negra e, principalmente, denunciou que o racismo, o preconceito e a discriminação racial estão presentes na sociedade e, consequentemente, nos currículos e práticas escolares.

A luta desse movimento não foi em vão, pois colocou na agenda política do País a urgência da criação de Políticas Públicas Afirmativas e de diversidade que vise à formulação, coordenação e articulação de políticas, diretrizes e ações voltadas à promoção da igualdade racial em todos os setores da sociedade. No campo da educação, foram implementadas legislações educacionais que colocaram o desafio aos sistemas de ensino, às

*Universidade Federal da Grande Dourados. Endereço eletrônico: wilkersolidade @ hotmail.com

**Universidade Federal de Grande Dourados. Endereço eletrônico: eugeniamarques@ufgd.edu.br 
escolas e aos docentes para a desconstrução de uma educação etnocêntrica que historicamente reforça a transmissão de estereótipos, preconceitos e inferiorização da diferença.

Nessa perspectiva, e como parte do projeto de pesquisa do programa de pós-graduação em Educação, o objetivo desse artigo é identificar os avanços e limites da Educação para as Relações Étnico-raciais nas escolas brasileiras. Para tanto, o trabalho está dividido em três seções. A primeira aponta o arcabouço jurídico e os estudos que fundamentaram a Educação para as Relações Étnico-raciais; a segunda seção tece considerações sobre a prática docente e a diversidade, e por fim, a última seção realiza um diálogo entre prática docente e os limites de sua ação, tendo como referência a análise de questionários aplicados a professores da rede estadual sul-mato-grossense de ensino.

\section{Educação e relações raciais: reflexões sobre legislações afirmativas}

As questões relacionadas à discriminação racial e educação, tanto no âmbito acadêmico quanto nos demais, têm sido objeto de um número crescente de publicações e estudos, favorecendo a abertura de espaços para discussões e buscas de alternativas para minimizar a discriminação racial e o preconceito nas escolas. Tais vertentes, inauguradas por trabalhos que desmascaram o "mito da democracia racial", têm contribuído para a exploração do assunto. Entretanto, quando falamos do racismo enquanto prática cotidiana, o quadro social desde o início do século XX até o momento atual pouco mudou.

Esta afirmação se evidencia no campo educacional através dos índices de alfabetização e escolaridade da população negra e indígena, e na relação discrepante quantitativa e qualitativamente entre elas e outros grupos. Vários estudos denunciaram o preconceito, a discriminação racial e as desigualdades raciais na educação, entre eles os realizados por Munanga (1996), Gonçalves (2000), Gomes (2001) e Cavalleiro (1999), diagnosticando que os negros e índios são penalizados tanto na educação por meio da exclusão do sistema formal de ensino, como também nas diversas esferas da vida social.

Com base nesses autores, focamo-nos na presença do educador frente a tal realidade, e para tanto, seguimos os trabalhos de Gonçalves (1985) e
Cavalleiro (2000) que analisam que o preconceito racial e a discriminação se proliferam nas escolas, através de mecanismos ou funcionamento dos rituais pedagógicos, estes entendidos como a materialização da prática pedagógica, vivenciada na sala de aula, a qual exclui dos currículos escolares a história de luta dos negros e/ou índios na sociedade brasileira. Cavalleiro (2000) é mais categórica ao dizer que é flagrante a ausência de um questionamento crítico por parte dos profissionais da escola sobre a presença de crianças negras e indígenas no cotidiano escolar.

Esse fato, além de confirmar o despreparo dos educadores para se relacionarem com os alunos negros e indígenas, evidencia também seu desinteresse em incluí-los positivamente na vida escolar, como parte de um todo homogêneo, sem especificidades ou necessidades próprias, desrespeitando as diferenças através do seu silenciamento.

O silêncio da escola sobre as dinâmicas das relações raciais tem permitido que seja transmitida aos (as) alunos (as) uma pretensa superioridade branca, sem que haja questionamento desse problema por parte dos (as) profissionais da educação e envolvendo o cotidiano escolar em práticas prejudiciais ao grupo negro. Silenciar-se diante do problema não apaga magicamente as diferenças, e ao contrário, permite que cada um construa, a seu modo, um entendimento muitas vezes estereotipado do outro que lhe é diferente. Esse entendimento acaba sendo pautado pelas vivências sociais de modo acrítico, conformando a divisão e a hierarquização raciais (CAVALLEIRO, 2006, p.23).

Esse quadro proporcionou combustível necessário aos movimentos sociais, para se empenharem em construir, ao longo da história, o que hoje chamamos tão naturalmente de "Cultura da Diversidade" ou "Diversidade Étnico-racial". Essas novas vertentes reflexivas, através do paulatino levante de questões relacionadas à discriminação racial e educação tanto no âmbito acadêmico quanto nas demais instituições, favoreceram aos poucos a abertura de espaços para discussões e busca de alternativas que minimizem a discriminação racial e o preconceito, independente de forma, nas escolas brasileiras e principalmente, no âmbito social. 
Essa transformação se traduziu, em uma de suas instâncias, nas legislações hoje vigentes no cenário educacional. As Leis 10.639/03 e 11.645/08 são seus reflexos principais. A primeira alterou a LDBEN (Lei 9.394/96) e incluiu no currículo escolar oficial a obrigatoriedade do ensino de História e Cultura Afro-Brasileira e de África e a Lei 11.645/08, modificando a Lei 10.639/03, estabeleceu as diretrizes e bases da educação nacional para incluir no currículo oficial da rede de ensino a obrigatoriedade da temática "História e Cultura Afro-Brasileira e Indígena".

O aparato legal simbolizado por essas leis, de certa forma, busca efetivar o que é de direito dos brasileiros: o conhecimento indiscriminado de sua cultura e valorização de sua identidade. Embasados nisso acreditamos que uma educação para a diversidade racial brasileira não pode, sem dúvida, prescindir do respaldo legal, entretanto, defendemos que a legislação só se concretiza no espaço escolar em uma dinâmica curricular e da sala de aula que privilegie uma educação anti-racista com conteúdo anti-racista (OLIVEIRA, 2009). Dessa forma, para que ela se efetive, os profissionais da educação, com enfoque aos docentes, necessitam de uma concepção que lhes garanta o domínio dos conteúdos a ensinar, no sentido amplo do termo, que inclua os valores que tal tipo de educação deverá privilegiar e de uma pedagogia que lhe permita manipular tais conhecimentos e privilegiar tais valores, colocando-os assim a serviço da equidade racial, cultural e de gênero.

Partindo dessa perspectiva, realizamos um diálogo sobre a definição do trabalho docente para com as coletividades, enfatizando sua importância na construção de posições anti-raciais a partir do processo de troca de conhecimentos, que aqui ousamos inserir na definição de práxis, bem como, da compreensão do papel do educador no processo de formação dos atores sociais.

\section{A prática docente na perspectiva da diversidade}

$\mathrm{Na}$ educação pública, existem várias práticas pedagógicas isoladas voltadas para a diversidade étnico-racial em todo o país. Há relatos de experiências mais familiarizadas com a inserção da Lei 10.639/03, bem como da 11.645/08 nos Projetos Pedagógicos, trabalhos conjuntos com a comunidade, movimento negro, projetos interdisciplinares, comemoração do dia nacional da consciência negra, do índio, estudos sistemáticos sobre o continente africano, cultura e artesanato indígena e projetos realizados com a participação dos estudantes de áreas de reserva indígena e quilombola.

Entretanto, apesar da existência de tantos movimentos/ações antirracistas, o racismo ainda se faz presente no cotidiano escolar. Nos dizeres de Kadlubitski e Junqueira (2010, p. 184), mesmo com os avanços nos documentos oficiais do Brasil ainda permanece hoje "uma presença difusa e confusa da diversidade na prática pedagógica, não existindo uma orquestração de propostas, projetos e práticas" realmente eficazes. Os trabalhos produzidos na área trazem declarações de tipo normativo, explanando que para alcançarem a dimensão objetiva, as práticas e ações pedagógicas necessitam efetivamente incorporar a formação de profissionais da Educação nos hábitos e costumes das práticas sociais, e não apenas atividades isoladas.

A necessidade da incorporação mais incisiva das relações étnicas e raciais no processo de formação do docente deve ser encarada como uma necessidade urgente. As pesquisas já realizadas em âmbito nacional demonstram que o ser docente, à medida que se avança os debates sobre a temática e sua dimensão social, passa a ser entendido como o possível proponente de uma ação mediadora entre a formação do aluno na vida cotidiana, da qual ele se apropria de forma espontânea da linguagem, dos objetos, dos usos e dos costumes através do convívio social, e a formação do aluno nas esferas não cotidianas dessa vida social, dando possibilidade de acesso a objetivações como ciência, arte, moral, etc, e possibilitando, ao mesmo tempo, o aguçar de sua postura crítica (DUARTE, 1993) para com as diversidades.

Entendida como educação formal, essa mediação entre o aluno e a cultura apresenta características distintas, pois é qualitativamente diferente de outras formas de educação, por ter como finalidade específica propiciar a apropriação de instrumentos culturais básicos que permitam a elaboração de entendimento da realidade social e promoção do desenvolvimento individual (BASSO, 1995). Essa proposição adjetiva a atividade pedagógica do professor como sendo a de um conjunto de ações intencionais, conscientes, dirigidas para um fim específico e com dimensão para além dos muros da escola.

Contudo, vale lembrar que o professor também é um indivíduo social, e propor uma prática docente na perspectiva das relações étnico-raciais 
como parte de uma ação pedagógica é no mínimo desafiador. Para facilitar uma discussão nesse viés, propomos um debate sobre o entendimento do termo "ação", utilizado por vezes neste texto, e que se aplica na prática docente. A definição de "ação", aqui empregado, se pauta nos trabalhos de Tardif e Lessard (2012). Para estes autores, "ação", quando se pensa no trabalho docente, deve ser entendida como o próprio processo de ensinar, não se definindo apenas em fazer algo, mas fazer com alguém alguma coisa significativa: o sentido que se permuta em classe, as significações comunicadas, reconhecidas e partilhadas (TARDIF; LESSARD, 2012, p. 249), uma atividade comunicada e direcionada, que resulte não apenas no objetivado pelo planejamento.

Dentro dessa ação, o professor ao comunicar-se com o aluno o faz não apenas de maneira a trabalhar a capacidade de aprender de cada indivíduo, mas sim, com a habilidade coletiva de receber a comunicação e transformá-la em significação. Com atividade direcionada primeiramente a um coletivo, a partir da ação de um sujeito que fala, a definição de trabalho docente deve partir também da concepção de atividades humanas individuais e coletivas, no qual o indivíduo como integrante coletivo de um todo participa ativamente no processo de construção do conhecimento, com práticas e instrumentos específicos, por ser ele, interativo e possuir características próprias das particularidades ontológicas de existir, como defende Vasconcellos (2003).

Esse processo, denominado de "açãoreflexão", tende a fazer parte da formação docente, definindo assim possibilidades diferentes de ensinar, de perceber os alunos - o aluno - e a natureza dos conhecimentos a serem construídos a partir do momento em que se propõe fazer, direcionando numa perspectiva que compõe esse trabalho, imbuindo no discurso o referencial de que a diversidade cultural é a riqueza da humanidade (GADOTTI, 2012, p. 47), e que para cumprir sua tarefa humanista, o professor precisa mostrar aos alunos que existem outras culturas além da sua, e que estas são passíveis de diálogo.

Atenção dobrada deve existir ao propor este diálogo. A exposição, crítica e debate devem ser estruturados a partir da conexão com os conhecimentos dos alunos, da sociedade, das interfaces dos conteúdos e das concepções filosóficas que enraízam as condições naturais e sociais destes como objeto humano, pois estes não são apenas seres psicobiológicos, como explica Tardif e Lessard (2012), são também seres sociais parcialmente definidos por uma situação socioeconômica, portadores de valores, crenças, interesses, e principalmente de indeterminações e de diferenciações (TARDIF; LESSARD, 2012, p.70).

$$
\text { Faz-se necessário então o }
$$

redimensionamento do olhar do educador, convergente a uma mudança de linguagem, reflexão da prática, e uma ação interdisciplinar voltada à construção de um perfil profissional vinculado à pesquisa no espaço escolar - ação/reflexão -, o que na ótica das relações étnico-raciais remete ao entendimento de uma desconstrução de noções e concepções apreendidas durante a vida nas práticas sociais em ambientes diversos.

Essa participação ativa aluno/professor, aluno/aluno, não apenas promove a superação dos antigos fazeres pedagógicos, como a mudança daquela atitude amorfa, bem como traz à tona uma imprescindivel conscientização por parte do educador que atua no Ensino Fundamental de seu compromisso com a educação do sujeito. Isso implica uma nova prática pedagógica, apoiada no conhecimento científico, em concepções definidas, na segurança, no envolvimento com a formulação de um projeto pedagógico adequado ao contexto escolar (OSÓRIO, 2003, p.220).

Entretanto, essa nova prática não se faz apenas com uma simples alteração de técnicas ou recursos metodológicos. $\mathrm{O}$ seu caminho transformador é diferente, pois se trata de uma reconstrução do próprio ser docente, que, como tal, deve partir do que o sujeito tem de história pessoal e profissional, e em se tratando do sujeito coletivo, há que se levar em conta, inclusive, sua história institucional e social, e somente deste modo vislumbrar possibilidades do enraizamento de uma nova postura, e consequentemente a nova prática.

O papel do professor, partindo daí, deixa de ser visto apenas como de um agente exclusivo de informação e formação dos alunos, centrando agora sua principal característica como a de ser o mediador das interações entre os alunos e destes com o novo, o diverso, o diferente.

Ou seja, seu objetivo é o desenvolvimento 
de um trabalho de acordo com um conceito progressista de educação; a relação educadorleducando exige, por parte dos educadores, uma atitude de respeito, valorização, confiança e disponibilidade para ajudar o aluno na construção de novos conhecimentos, contribuindo para a preparação de cidadãos participativos, autônomos, críticos e reflexivos (OSÓRIO, 2003, p.235).

Dessa forma, é compreensível que não se pode discutir o trabalho docente com a premissa da diversidade étnico-racial, cultural, social, de orientação sexual, religiosa, etc, apenas pelo seu caráter objetivo ou utilizando como escudo de defesa as bases que a própria legislação oferta, pois tal atitude conduz à crença na possibilidade de falar em educação desconsiderando a importância da subjetividade existente nas "atividades simples" do próprio processo do ensinar, e da compreensão da individualidade coletiva presente no processo educativo.

Mas, e se considerarmos apenas a própria legislação vigente, como se efetiva hoje a relação entre educação e diversidade étnico-racial no espaço escolar? Com base neste questionamento nos propomos a realizar a pesquisa que aqui apresentamos, tendo como pano de fundo a possibilidade de uma ação pedagógica transformadora, e se pautando no decênio da promulgação da lei 10.639/03, fomos para a escola buscar vestígios de como é tratada as temáticas étnico-raciais e suas derivadas neste espaço.

\section{Educação e diversidade étnico-racial: entre o prescrito e o vivido}

É consenso dos pesquisadores em educação a existência de uma identidade específica em cada indivíduo, como já mencionamos, mas a possibilidade de trabalhar em sala com as culturas que convergem numa concepção única de cultura no país, partindo da ótica das diversas identidades, ainda significa algo muito dispendioso se considerarmos as adversidades que o cotidiano escolar, a comunidade a que ela pertence, a gestão, etc, impõem.

Nesse entendimento buscando mensurar como a lei 10.639/03 foi sendo trabalhada no processo formativo docente, e como ela está se refletindo em sala de aula, propondo para isso o trabalho com questionários aplicados a um grupo de professores que cursam uma Especialização para Profissionais da Educação. A ideia inicial da pesquisa era de discutir a temática no curso de especialização, mas alteramos seu rumo ao perceber o quão rasas eram as discussões envolvendo o conceito de diversidade na escola. Vale ressaltar que todos os participantes da pesquisa são profissionais que atuam nas séries iniciais e finais do ensino fundamental, em escolas públicas e privadas do município de Dourados/MS.

A metodologia adotada partiu da aplicação do questionário composto por quatro questões abertas, seguido de uma exposição discursiva com base na teoria sobre a temática étnico-racial e o espaço escolar, e por fim uma roda de conversa sobre as possibilidades da temática ser mais presente no cotidiano escolar. As questões que compuseram o questionário pautavam-se na Lei 10.639/03 e na presença de resquícios de discriminação racial no ambiente escolar, centrando acepção da ação-reflexão docente a partir da prática pautada nas normativas escolares. As questões aplicadas foram: O que você sabe sobre a Lei 10.639/2003?; Existe na escola situações que envolvem relatos de preconceito e discriminação racial? (Explícito ou não, por exemplo, em forma de brincadeiras, apelidos ou bullying)?; Quais as dificuldades para implementação da Lei 10.639/203 nas escolas de um modo geral; Você já participou de algum curso de formação continuada sobre a Educação para as relações étnico-raciais e para a implementação da Lei 10.639/2003?

Os dados expuseram que o conhecimento legislativo teórico acerca da necessidade de reconhecimento e valorização das diversas culturas que compõem a sociedade brasileira se faz presente na rotina docente, estando no contato com os livros didáticos e os Planos Pedagógicos, o principal responsável pela disseminação dos caminhos trilhados para "heterogeneização" cultural, conforme Cavalleiro (2010). Ponto este, evidenciado quando às respostas para o primeiro questionamento, na qual todos os profissionais puderam definir, de maneira diversa, qual o teor da lei.

Na sequência, o segundo item questionado, expôs a existência de atitudes de discriminação racial no ambiente escolar, estas mascaradas, muitas vezes, em forma de brincadeiras, piadas, bullying, etc. Dos questionários, apenas $32 \%$ relataram não ter presenciado pelo menos alguma vez formas de 
discriminação racial, sendo $12 \%$ destes justificados pela existência de preconceito "somente" para com a orientação sexual ou características físicas.

$A h$, normalmente a gente vê os meninos xingando uns aos outros de bicha, viado, coisas do tipo. Mas porque é preto eu nunca vi não. Já ouvi a criançada falar que o coleguinha é gordo, chamar de apelidos, mas realmente sobre a cor da pessoa eu nunca ouvi (Professor A, 2014).

Este item nos leva a refletir que mesmo com ações direcionadas à aquisição de valores culturais diversos, a escola continua a perpetuar atitudes arcaicas. Atitudes estas poucas vezes trabalhadas em sala de aula, que acabam por solidificar uma posição passiva da escola para com o preconceito racial, e essa posição, denominada de "silêncio escolar" por Eliane Cavalleiro (2005), finda por engessar uma cultura preconceituosa dentro da própria escola, e sendo ela uma extensão da sociedade em que está inserida, forma atores sociais com uma "eterna" postura de preconceito e discriminação para com o diverso, estendemos essa percepção não somente no que tange a questão de cor, mas também de gênero, culto, etc.

Um valor muito impactante é $68 \%$. Se todo este quantitativo já presenciou algum tipo de preconceito ou discriminação racial, quais atitudes poderiam ser tomadas para mudar tal realidade? Uma das participantes da pesquisa justificou que:

Eu ouvi na turma do $4^{\circ} \mathrm{D}$ uma criança chamando a outra de Cirilo, o personagem do SBT. Daí eu perguntei pra ele porque ele estava chamando o colega de Cirilo, já que este não era o nome dele. Ele me respondeu que o colega era "pretinho" igual o Cirilo, e simpático, justificando que não era xingamento, e sim um elogio. Eu não soube $o$ que fazer. Então disse que não o chamasse mais pelo nome do personagem porque o colega tinha nome, e que eu não aceitava apelidos em sala de aula. Isso pode ser considerado racismo? (Professor $B$, 2014).

A realidade exposta pela professora é a de muitos outros no país. A mídia, principalmente a televisiva, há muito tempo atua na formação de uma imagem não positiva do indivíduo negro, e por estar o professor também na frente do televisor, este não consegue perceber as amarras existentes na figuração do personagem negro e a inferioridade, ou ingenuidade deste, para com o cenário.

Quanto a isso, Lahni já é enfática ao falar sobre o negro e a mídia. Para ela a mídia absorve, reelabora e transmite $\mathrm{o}$ imaginário coletivo nas representações sociais.

Como fica o negro na mídia? Não muito diferente da sua realidade social. É verdade que a realidade está se modificando, o problema é que essa mudança é muito lenta. Enquanto isso os afro-brasileiros que estão à margem da sociedade desde a abolição da escravatura (e durante a escravidão), agora continuam marginalizados nas favelas, com acesso precário ao estudo e emprego e também sem ser representados na sociedade (cargos políticos) e na mídia (jornalistas, atores e personagens que realmente identifiquem os afro-brasileiros) (LAHNI, 2007 p. 83).

A mídia é, quase sempre, utilizada para servir o interesse de coletivos específicos dentro da sociedade, geralmente aqueles que fazem parte dos grupos hegemônicos, e por isso muitas vezes, ela lança olhares racistas e expressa conteúdos preconceituosos, quando os assuntos tratados fazem referência principalmente aos negros, como é bem retratado nas pesquisas desenvolvidas por Leitão (2002), Alakija (2012), Conceição (2005), Araújo (2000), Nascimento (2012), Perez (2011), etc.

Utilizamos o termo "quase sempre" porque é perceptível uma mudança nos últimos anos na representação do negro na mídia aberta brasileira. Mesmo em paralelo a insistente figuração do negro em profissões de menor prestígio social, ou em situações ligadas a criminalidade ou exposição sensualizada do corpo, há uma ascendente exposição de personagens negros com sucesso profissional e reconhecimento social nas telenovelas e filmes nacionais.

Mas voltando ao questionário, ao perguntar sobre as dificuldades para a implementação da lei, tivemos diversas pontuações interessantes. Um total de $13 \%$ dos entrevistados direcionou ao livro didático a principal barreira existente para a implementação da lei, acusando o livro de ser uma ferramenta de manipulação do governo. 
O livro é o que mais atrapalha na hora de trabalhar o que a lei manda porque ele vem com conteúdo todo direcionado e como a gente tem que seguir aquilo, fica difícil propor algo diferente que não foge do que já está ali. Ele define quais os caminhos que a gente tem que trilhar e põem a gente para levar as crianças pelas mãos (Professor A, 2014).

A forma com que o conteúdo aparece no livro didático e no material enviado às escolas são os maiores limitadores da lei, porque eu penso que eles poderiam ser mais dinâmicos e pontuarem alguns aspectos ainda vivos destas culturas em nossa sociedade. Expõe sobre a cultura africana e afro-brasileira, mas não contextualiza com o cotidiano de hoje. Daí a gente que trabalha ha tanto tempo na escola vê aquilo como algo tão novo quanto para os alunos quando vamos passar (Professor B, 2014).

Estes dois recortes expõem que o professor ainda se vê preso ao livro didático. Este que deveria ser uma ferramenta de apoio, ao que parece, está sendo interpretado como um manual a se seguir fielmente. O material didático é um suporte, servindo como subsídio de aprendizagem e conhecimento na formação do educando, tornandose um instrumento de auxílio nas mãos dos educadores. Entretanto, alguns livros não dão suporte necessário aos educadores, e com isso, a tarefa de interpretar os conteúdos, imagens ou símbolos que o livro traz torna-se muito difícil, e aí o termo "mais dinâmico" citado pela entrevistada, a nosso ver, traduz de forma clara a maior barreira do suporte didático ofertado: não basta citar a legislação ou a existência dessa parcela da população, até mesmo porque os alunos são parte deste todo, mas é necessário manter um contato entre o conteúdo e a realidade social.

Em contrapartida, houve respostas que centraram no livro e material didático a principal ferramenta de disseminação do que a lei elenca, por trazerem de forma direcionada o que deve ser entendido como cultura afro-brasileira, e ao utilizarse de marcos (como o dia da Consciência Negra) como referência para a efetivação do preconizado, insere no cotidiano escolar a temática.

$\mathrm{O}$ interesse por parte do profissional também foi pautado como fator preponderante na aplicabilidade ou não da lei. Com um total de $19 \%$ das respostas, esta concepção reforça que o educador, como indivíduo e ator social, deve também buscar sua atualização contínua para com a educação nacional, pois, à medida que entende as carências sociais, pode embasar-se teoricamente em formas de defesa e qualificação, pautado é claro, na ciência dos reflexos de suas ações.

A sociedade, esta na qual a instituição escolar está inserida e da qual capta características deterministas, é tida como referência também para com as dificuldades de implementação da legislação em pauta, somando um quantitativo de $18 \%$ dos apontamentos. Para os educadores, a sociedade, rodeada de valores intrínsecos em sua própria essência, acaba por formar uma barreira subjetiva para a formação de uma consciência social pautada na diversidade cultural, seja ela étnica,religiosa ou de gênero, estando sempre chamuscada de pequenos/grandes preconceitos, estes entendidos como naturais, e refletidos na postura do educando, e muitas vezes do educador, para com tudo o que é diferente.

A grande dificuldade para a implementação, tendo em vista $37 \%$ de apontamentos existentes, expõe a deficiência no campo das capacitações profissionais as quais os docentes devem ter acesso. Fato esse evidenciado também quando analisamos o último item questionado.

Ao perguntar sobre a participação dos entrevistados em cursos de capacitação que abordavam tal temática, apenas $25 \%$ estiveram em contato com a legislação $10.639 / 03$, sendo que $6 \%$ destes realizaram a capacitação fora da escola e $12 \%$ haviam conhecido a legislação durante o curso de graduação.

Fator alarmante este, pois, à perspectiva de uma análise da ação profissional pautada na formação docente, tendo em vista que muitos destes profissionais tenham se graduado antes dos anos de 2003, nos identifica uma tendência em seguir apenas o que o livro didático tem a oferecer, sem conhecer a transformações sociais que convergiram no que hoje é refletido na escola.

Em síntese, mesmo que a legislação, as normativas governamentais, bem como os programas direcionados à questão da diversidade étnico-racial atuem de forma preponderante no cenário educacional, podemos ousar dizer que, ainda assim, isso não se faz suficiente se não houver uma massificação de ações, principalmente no que se refere à formação continuada dos docentes, pois 
os educadores estão saindo das universidades com uma quantidade significativa de conceitos em seus currículos, mas que ainda não são suficientes para atuarem de forma satisfatória no que se refere à diversidade no ambiente escolar.

A legislação em si não faz uma mudança, e o fato de os professores não participarem de formação para com o trato dessas mudanças em sala, são no mínimo, características de que o poder externo à escola entende que a inserção no livro didático do que a lei prepondera já é o suficiente. Assim, como é possível trabalhar a alteridade, a práxis ou qualquer outra forma de valorização de identidade se não há base na escola para isso? Como o educador conseguirá identificar alguma forma de discriminação racial, e trabalhar isso em classe para sua erradicação, se também a pratica?

Enfim, a ação docente sozinha não consegue lutar contra o que está enraizado, fixado nos pilares da sociedade. Temos ciência que a academia hoje, por meio de pesquisas e trabalhos relacionados à perspectiva étnico-racial $\mathrm{e}$ as diversidades, almeja uma transformação social. Mas devemos nos ater no ideário que, somente através da teoria não se pode alcançar os objetivos elencados pela lei. A escola é um espaço propício para que se discutam as diferentes culturas, sociais e raciais, mas para tanto é fundamental que se construa um caminho, e este se faz com a abrangência totalitária da sociedade, na qual é essencial uma visão minimalista de todos os entraves que o indivíduo possa ter com o andar dessas transformações, seja este coletivo ou não.

\section{Considerações finais}

Voltando nossos olhares para as escolas de educação básica, várias são as razões elencadas pelos atores dos sistemas de ensino para a não implementação de educação anti-racista, das quais ganham destaque: o desconhecimento das Leis $10.639 / 03$ e 11.645/08; a falta de formação específica para as professoras e professores; a inexistência de livros e matérias didáticos que correspondam ao conteúdo proposto e a falta de recursos para investimento.

Nesse entendimento, como via de escape, podemos defender a possibilidade de debates permanentes entre os docentes quanto ao objetivo de sua ação, pois, num processo educativo de trocas e inter-relações de conhecimentos, se converge um modelo pedagógico, no qual os professores podem exercitar novas sociabilidades étnico-raciais e novas posturas nas suas subjetividades.

Entretanto, os obstáculos para uma transformação na ação docente vão mais além, pois a questão curricular se desdobra na necessidade de uma nova política educacional de formação inicial e contínua, para reverter positivamente às novas gerações, uma nova interpretação da história e uma nova abordagem da construção de saberes, continuaremos numa perspectiva de dúvida $\mathrm{e}$ incapacidades teóricas e práticas de enfrentar os conflitos iminentes das discussões étnico-raciais na educação.

Existe hoje uma necessidade indubitável de se incluir nos currículos e nas práticas pedagógicas as diferenças culturais de cada povo e cada raça para dar sentido e tornar possível a discussão da diferença racial no cotidiano escolar, tornando essas diferenças uma possibilidade de respeito e diálogo com as diversas identidades presentes cotidianamente na sala de aula, e fora dela.

Deste modo, como considerações parciais de nossa pesquisa, deixamos como pretensão de produções derivadas da proposta exposta pelo programa de pós-graduação da qual centramos nossos investimentos acadêmicos, investigar como estão sendo implementadas as políticas de valorização étnico-racial nas escolas sul-matogrossenses, no aspecto da construção do currículo voltado para a diversidade, não do ponto de vista dos legisladores ou dos gestores das políticas públicas, mas a partir das experiências vividas nos espaços escolares, nas opiniões, valores, conceitos, ideias, preferências, concepções de professores e educandos que ocupam esses lugares, abrindo espaço para novos vieses no que tange as diversidades, das quais se caracterizam a composição social brasileira.

\section{Referências}

ABBAGNANO, Nicola. Dicionário de Filosofia; tradução Alfredo Bosi. 2. ed. São Paulo: Martins Fontes, 1998.

BRASIL. Lei 10639/2003. Diário Oficial da União de 10 de janeiro de 2003.

BRASIL. Lei 11645/2008. Diário Oficial da União de 10 de março de 2008. 
Diretrizes Curriculares Nacionais para a

Educação das relações Étnico - Raciais e para o Ensino de História e Cultura Afro-Brasileira e Africana. Secretaria Especial de Políticas de Promoção da Igualdade Racial. Brasília: MEC, 2005. 35p.

BASSO, I.S. "Formação de professores: Contribuições da perspectiva histórico-social." Anais. Simpósio Formação de Professores: Tendências Atuais. São Carlos, UFSCar, 1995.

CAVALLEIRO, Eliane. Discriminação racial e pluralismo em escolas da cidade de São Paulo. In: Educação anti-racista: caminhos abertos pela Lei Federal n.10.639/2003.Secretaria de Educação Continuada, Alfabetização e Diversidade. Brasília: Ministério da Educação, 2005.

DUARTE, N. A individualidade para si. Campinas, Autores Associados, 1993.

GOMES, Nilma Lino et al. Identidades $e$ Corporeidades Negras: Reflexões sobre uma experiência de formação de professores/as para a diversidade étnico-racial. Belo Horizonte: Autêntica, 2006.

GONÇALVES, L.A.O. Negros e educação no Brasil. In: LOPES, E.M.T.; FARIA FILHO, L.; VEIGA, C.G. (Org.). 500 anos de educação no Brasil. Belo Horizonte: Autêntica, 2000. p. 325346.

KADLUBITSKI, Lídia; JUNQUEIRA, Sergio. Diversidade cultural na formação do Pedagogo. VIDYA, v. 30, n. 1, p. 25-41, jan./jun., 2010 - Santa Maria, 2010.

MUNANGA, Kabengele. Uma abordagem conceitual das noções de raça, racismo, identidade, etnia. Niterói: EDUFF, 2000.

OLIVEIRA, I. B. de. Boa Ventura e a Educação. Belo Horizonte: Ed. Autêntica, 2012.

OSORIO, Alda M. N (org). Trabalho docente: os professores e sua formação. Campo Grande, MS: Ed. UFMS, 2003.

SANTOMÉ, Jurjo Torres. As culturas negadas e silenciadas no currículo. In: SILVA, T. T. (Org.). Alienígenas em sala de aula: uma introdução aos estudos culturais em educação. Petrópolis: Vozes, 2003.

SOUZA, Maria Elena Viana. Educação étnicorracial brasileira: uma forma de educar para a cidadania. In: MIRANDA, C. LINS, M.R.F. COSTA, R.C.R. Relações Étnicorraciais na escola: desafios teóricos e práticas pedagógicas após a lei n. 10.639. Quartet editora: Rio de Janeiro, 2012.

TARDIF, Maurice. LESSARD, Claude. $O$ trabalho docente: elementos para uma teoria da docência como profissão de interações humanas. Tradução de João Batista Kreuch. Editora Vozes, Petrópolis/RJ, 2012.

VALENTE, A. L. Ação Afirmativa, relações raciais e educação básica. In: Revista Brasileira de Educação. N. 28. Rio de Janeiro: jan./fev./mar./abr. 2005.

VASCONCELlOS, Celso dos Santos. Para onde vai o professor? Resgate do professor como sujeito de transformação. $10^{\mathrm{a}}$ Ed. São Paulo: Libertad, 2003. (Coleção Subsideos Pedagógicos do Libertad; v.1)

VAZQUEZ, A. S. Filosofia da Práxis. 2a edição. Rio de Janeiro: Editora Paz e Terra, 1977.

\section{Sobre as autoras}

Wilker Solidade Silva é Mestre em Educação pelo Programa de Pós-Graduação em Educação, Universidade Federal de Grande Dourados.

Eugenia Portela Siqueira Marques é Doutora em Educação pela UFSCar e Professora do Programa de PósGraduação em Educação, Universidade Federal de Grande Dourados. 
Recebido em março de 2014.

Aprovado em abril de 2015.

Horizontes, v. 33, n. 2, p. 47-56, jul./dez. 2015 